Check for updates

Cite this: RSC Adv., 2019, 9, 26981

\title{
Calcined chicken eggshell electrode for battery and supercapacitor applications $\dagger$
}

\author{
Manickam Minakshi, (D) *a Stephen Higley, ${ }^{\text {a }}$ Christian Baur, (D) ${ }^{\mathrm{b}}$ David R. G. Mitchell, \\ Robert T. Jones ${ }^{\mathrm{d}}$ and Maximilian Fichtner (D) ${ }^{\mathrm{b}}$
}

Biowaste eggshell can be used as a cathode while in its calcined form and it is found to be suitable as an anode in an electrochemical cell. This not only enables energy to be stored reversibly but also achieves waste management and sustainability goals by redirecting material away from landfill. Biowaste eggshell comprises $94 \%$ calcium carbonate $\left(\mathrm{CaCO}_{3}\right.$; calcite), an attractive divalent ion source as a viable option for energy storage. X-ray diffraction and electron microscopy coupled with energy dispersive analyses of the calcined (thermally decomposed) biowaste eggshell show that $\mathrm{CaO}$ has been formed and the reaction is topotactic. Field emission scanning electron microscopy (FESEM) images of the textural relationship show that the thermal decomposition of calcite resulted in a change in morphology. High-resolution XPS spectra of the $\mathrm{C}$ 1s core level from the $\mathrm{CaCO}_{3}$ and $\mathrm{CaO}$ shows that there is a chemical difference in the carbon environments and the total atomic fraction of $\mathrm{Ca}$ for each sample with that of carbonate and oxygen varies. In a three-electrode configuration, a working electrode of $\mathrm{CaCO}_{3}$ is found to be electrochemically active in the positive region, whereas a $\mathrm{CaO}$ electrode is active in the negative region. This indicates the potential use of eggshell-derived materials for both cathode and anode. Both the electrodes exhibited a quasi-boxshaped potentiostatic curve implying a capacitor-type behaviour. The $\mathrm{CaCO}_{3}$ cathode possesses a modest discharge capacitance of $10 \mathrm{~F} \mathrm{~g}^{-1}$ but the $\mathrm{CaO}$ anode showed excellent capacitance value of $47.5 \mathrm{~F} \mathrm{~g}^{-1}$. The $\mathrm{CaO}$ electrode in both positive and negative regions, at a current density of $0.15 \mathrm{~A} \mathrm{~g}^{-1}$ exhibited $55 \mathrm{~F}$ $\mathrm{g}^{-1}$ with a retention of nearly $100 \%$ after 1000 cycles. At a very low sweep rate of $0.5 \mathrm{mV} \mathrm{s}{ }^{-1}$, the CaO electrode showed typical redox-type behaviour with well-defined peaks illustrating battery-type behaviour. The outcome of the calcite/CaO transformation, exhibiting technological importance for energy storage applications, may help to re-evaluate biowaste before throwing it away. The current work explores the viability of eggshell derived materials as a cathode/anode for use in batteries and capacitors.

\author{
Received 7th June 2019 \\ Accepted 15th August 2019 \\ DOI: $10.1039 / c 9 r a 04289 j$ \\ rsc.li/rsc-advances
}

\section{Introduction}

With the issues surrounding large-scale fossil fuel use, increasing demand for energy and environmental pollution, intense research has been focused on clean energy and renewable sources. Wind and solar-generated electricity is becoming increasingly available across the world, while storage in rechargeable batteries and supercapacitors is a promising solution to ensure consistent energy supply. ${ }^{1}$ Electrochemical means of energy storage is considered to be environmentally friendly and efficient. ${ }^{2}$ Sustainability means that the product can be produced at a certain rate while causing little or no damage to the environment and not exhausting resources.

\footnotetext{
${ }^{a}$ Engineering and Energy, Murdoch University, WA 6150, Australia.E-mail: minakshi@ murdoch.edu.au

${ }^{b}$ Helmholtz Institute Ulm for Electrochemical Energy Storage (HIU), Ulm 89081, Germany

${ }^{c}$ Electron Microscopy Centre, University of Wollongong, NSW 2500, Australia ${ }^{d}$ Centre for Materials and Surface Science, La Trobe University, VIC 3086, Australia $\dagger$ Electronic supplementary information (ESI) available. See DOI: 10.1039/c9ra04289j
}

Electrode materials play a significant role in the development of high-performance batteries and supercapacitors. Researchers have focused their efforts mainly on improving the properties of electrodes, such as increasing surface area, improving the conductivity through additives, introducing desirable electroactive sites in the electrode materials etc. ${ }^{3-5}$ The primary electrodes utilised for supercapacitor applications are carbon materials; $2 \mathrm{D}$ nanomaterials; conducting polymers; and metal oxides such as NiO, $\mathrm{Co}_{2} \mathrm{O}_{3}$, and $\mathrm{V}_{2} \mathrm{O}_{5} \cdot{ }^{4}$ Metal oxides are considered the most promising materials for electrochemical supercapacitor applications due to their physicochemical properties. ${ }^{4}$ On the other hand, phosphates are considered to be excellent candidates for battery applications, due to their structural stability. Numerous research and development efforts have been devoted to investigating electrode materials with excellent electrochemical performance, so as to increase the energy density and storage capacity of supercapacitor and battery systems. ${ }^{3-5}$ However, to the best of our knowledge, most of the reported work on electrode materials in the literature ${ }^{3-8}$ is related to the chemical synthesis route of oxides and phosphates by virtue of their high electrochemical activity, low cost and ready availability. 
Such materials are not sustainable unless they are recycled; therefore, it is of great importance to explore novel electrode materials that are both renewable and exhibit superior performance characteristics. Technological breakthroughs from identifying novel and sustainable materials will contribute to the development of nextgeneration energy storage systems.

Regarding the fact of entropy expressed in the laws of thermodynamics, the need to innovate sustainable and conservative waste management ${ }^{9}$ initiatives means extra costs can be offset by reducing synthetically manufactured products. The use of a waste product (eggshell) in energy storage applications reduces pressure on landfill, converts a negative value (disposal cost) waste into a high positive value product and also avoids the need for energy intensive and polluting mining/refining to source metal oxide alternatives. Chicken eggs are used in enormous quantities in the food processing and manufacturing industries, restaurants, households and even in the pharmaceutical industry, and their shells are disposed as solid waste. ${ }^{\mathbf{1 0}}$ Moreover, discarding eggshell solid waste to landfill is associated with a cost, depending on the location of the landfill. The thermal decomposition of calcite $\left(\mathrm{CaCO}_{3}\right)$ has been the subject of extensive research over a number of years with the quicklime ( $\mathrm{CaO}$ ) product being widely used in the food, cement and agricultural sectors. However, the application of eggshell-derived materials in energy storage is largely unexplored. ${ }^{\mathbf{1 0}}$ Nevertheless, bio-waste chicken eggshells in the form of $\mathrm{CaCO}_{3}$ has been explored by the authors in nonaqueous electrolyte for Li-ion capacitors. ${ }^{11}$ In another study, ${ }^{12} \mathrm{CaO}$ derived from bio-waste impregnated activated carbon has been reported as an electrode for supercapacitors. To the best of our knowledge, role of calcite/CaO transformation as a cathode/anode material for use in batteries and capacitors and its redox behaviour has not been reported in aqueous electrolyte.

Herein, the aim is to show that both the eggshell and its calcined form are sustainable materials for storing renewable energy. In order to study the electrochemical properties,

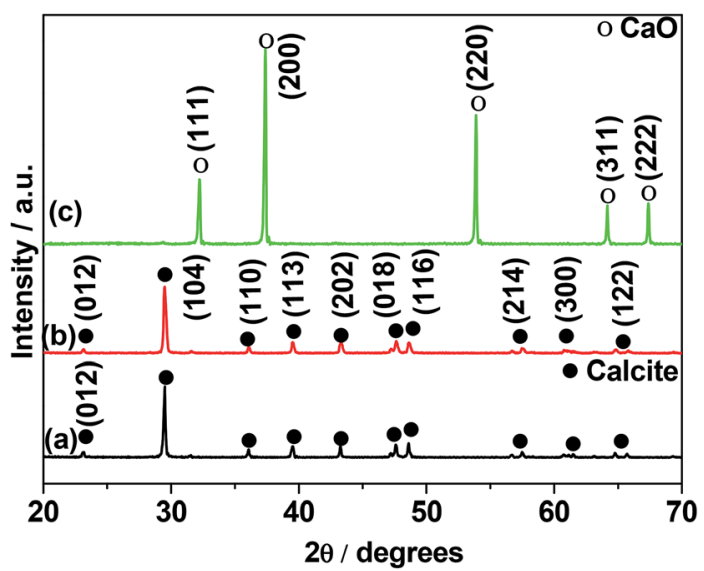

Fig. 1 X-ray diffraction (XRD) patterns of chicken eggshell (a) ascrushed; and calcined at: (b) $600{ }^{\circ} \mathrm{C}$ and (c) $900{ }^{\circ} \mathrm{C}$. The lower temperature $\mathrm{CaCO}_{3}$ material displayed a much weaker pattern, suggesting it was not a much crystalline. a typical cell with three-electrode configuration was constructed. In a three-electrode setup, the working electrode (eggshell) is in contact with an ionic conducting electrolyte $(\mathrm{NaOH})$. Batteries have both a chemical and a capacitive component and so another objective of this work is to explore these characteristics by focussing on a single electrode in a wide electrochemical window and test its suitability for a symmetrical supercapacitor studies. The insights drawn in this work demonstrate the potential of eggshell as a valuable sustainable resource for future developers of renewable and sustainable technologies. The incentive to integrate a sustainable resource like eggshell into the renewable energy market becomes selfevident from the results shown.

\section{Experimental}

The chicken eggshell was obtained from a local supermarket and comprised both calcified shell and shell membranes including inner and outer membranes. These were washed, oven-dried, and then crushed to a powder using mortar and pestle. In detail, a sample of chicken eggshells were soaked in sodium hypochlorite for $5 \mathrm{~min}$ for removal of shell membrane. Then, precipitated solid particles were washed in water and oven dried overnight. Later, the samples were crushed and stirred in water, and finally heat treated at two different temperatures $\left(600{ }^{\circ} \mathrm{C}\right.$ and $\left.900{ }^{\circ} \mathrm{C}\right)$ for $3 \mathrm{~h}$. Calcite $\left(\mathrm{CaCO}_{3}\right)$ was obtained at lower temperature, and $\mathrm{CaO}$ at a higher temperature.

A fine calcined eggshell powder (70 wt\%) was mixed with carbon black (20 wt\%), and polyvinylidene fluoride (PVDF) binder (10 wt\%) with $0.4 \mathrm{~mL}$ of $N$-methyl-2-pyrrolidine (NMP) to make a slurry. Approximately $10 \mathrm{mg}$ of the composite was coated onto a $1 \mathrm{~cm}^{2}$ graphite sheet as a current collector. While the working electrode was constructed with the eggshell composite as the positive electrode, a platinum wire of $10 \mathrm{~cm}$ length and $1 \mathrm{~mm}$ diameter, and mercury-mercuric oxide $(\mathrm{Hg} /$ $\mathrm{HgO}$ ) served as the counter and reference electrodes, respectively. The electrolyte used was $2 \mathrm{M} \mathrm{NaOH}$. Galvanostatic charge-discharge and cyclic voltammetry experiments were performed using the SP-150 model from Bio-Logic Science Instruments. Electrochemical impedance spectroscopy (EIS) was carried out using a sinusoidal signal with an amplitude of $10 \mathrm{mV}$ over a frequency range of 500000 to $0.01 \mathrm{~Hz}$.

The phase purity of the as-synthesized sample was characterized by powder X-ray diffraction (XRD, Philips PANalytical, Bruker D8) analysis using $\mathrm{Cu}-\mathrm{K} \alpha$ radiation at an accelerating voltage and current of $40 \mathrm{kV}$ and $30 \mathrm{~mA}$, respectively. In situ Powder XRD (PXRD) experiments were conducted by using a STOE STADI-p diffractometer in transmission geometry with Mo $\mathrm{K}_{\alpha 1}$ radiation $(0.070932 \mathrm{~nm}$ ), equipped with a DECTRIS MYTHEN 1K strip detector and a STOE capillary furnace. The samples were introduced in quartz capillaries and heated at a rate of $10{ }^{\circ} \mathrm{C} \mathrm{min}^{-1}$ from room temperature (RT) to $900{ }^{\circ} \mathrm{C}$ and then cooled naturally to room temperature. PXRD patterns were recorded every $50{ }^{\circ} \mathrm{C}$ with $1 \mathrm{~h}$ exposure. Thermogravimetric analysis and differential thermal analyses (TG-DTA) were carried out using a PerkinElmer STA 6000 thermo-balance at a heating rate of $20{ }^{\circ} \mathrm{C} \min ^{-1}$ in a static air atmosphere. The 
morphology of the eggshell material was characterized by Mira VP - Field Emission Scanning Electron Microscope (FESEM). High-magnification imaging of the eggshell material was carried out using transmission electron microscope on a JEOL ARM 200F TEM operated at $200 \mathrm{kV}$. TEM specimens were prepared by grinding a small amount of powder in ethanol and dispersing it on a holey carbon film. Brunauer, Emmett and Teller (BET) surface area measurements and porosity analysis were also carried out by Micromeritics Tristar II surface area and porosity analyser. For porosity measurements, all samples

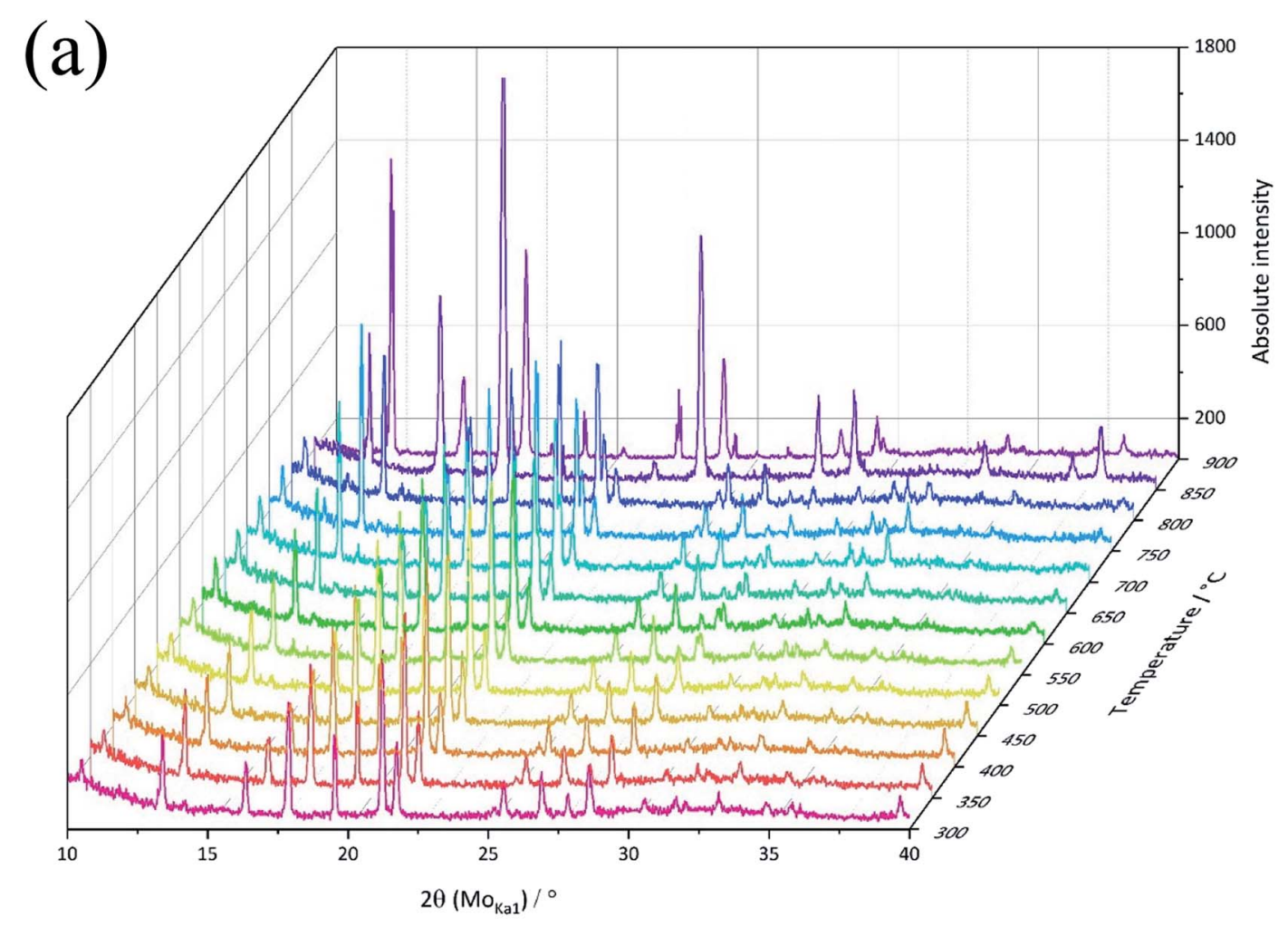

(b)

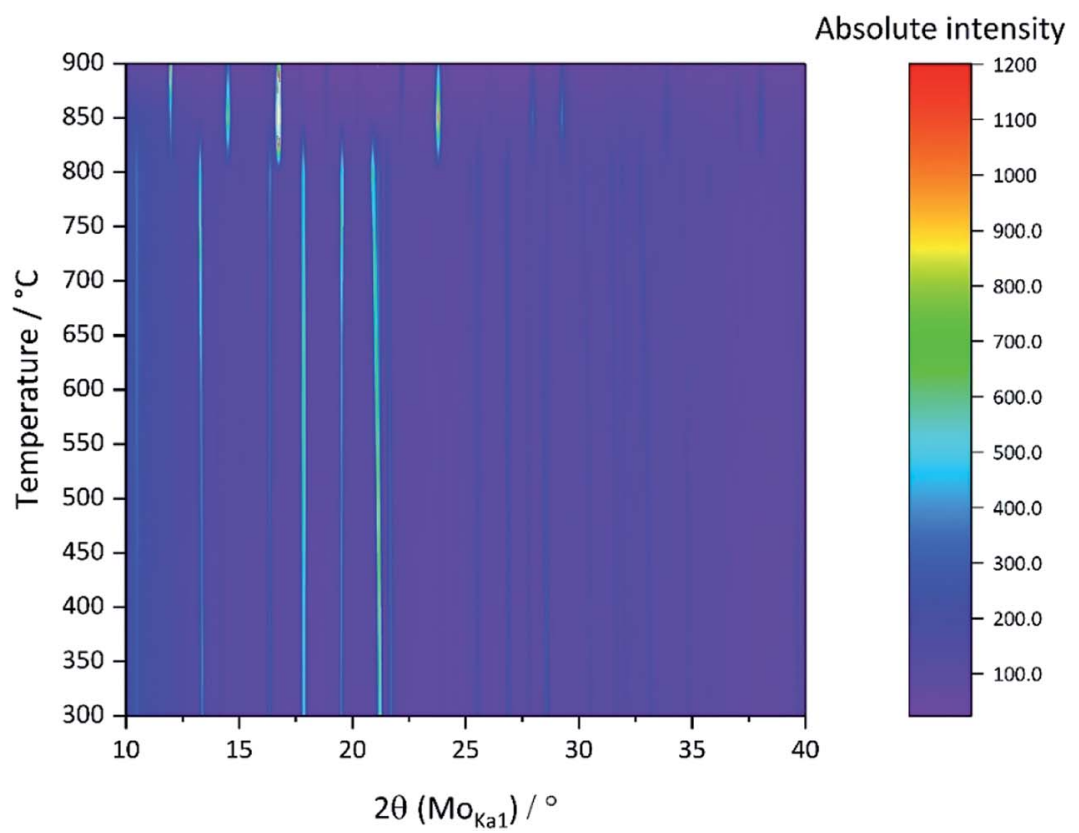

Fig. 2 (a) X-ray diffraction (XRD), and (b) corresponding top view of the patterns of chicken eggshell synthesized from room temperature to $900{ }^{\circ} \mathrm{C}$, various profiles are stacked in the image. 
were degassed at $100{ }^{\circ} \mathrm{C}$ overnight in vacuum before analysis. $\mathrm{X}$ ray photoelectron (XPS) spectra were acquired using a Kratos AXIS Ultra instrument (Kratos Analytical Ltd, U.K.) equipped with a monochromated $\mathrm{Al} \mathrm{K} \alpha$ radiation source $(1486.69 \mathrm{eV})$ operating at $150 \mathrm{~W}$ power $(15 \mathrm{kV}, 10 \mathrm{~mA})$. Analysis chamber pressure was $<3 \times 10^{-9}$ mbar. High-resolution spectra acquired for selected photoemissions were recorded at $0.1 \mathrm{eV}$ per step and with a pass energy of $20 \mathrm{eV}$. The analysis area was approx. $300 \mu \mathrm{m} \times 700 \mu \mathrm{m}$.

\section{Results and discussion}

Phase evolution with temperature (calcination): XRD and TGA analyses

The crystal structure and purity of the biowaste eggshell (as crushed), and calcined at two different temperatures $\left(600{ }^{\circ} \mathrm{C}\right.$ and $900{ }^{\circ} \mathrm{C}$ ) for $3 \mathrm{~h}$ were investigated using X-ray diffraction (XRD). The XRD peaks for both as-crushed (Fig. 1a) and $600{ }^{\circ} \mathrm{C}$ calcined sample (Fig. 1b) are in good agreement with the
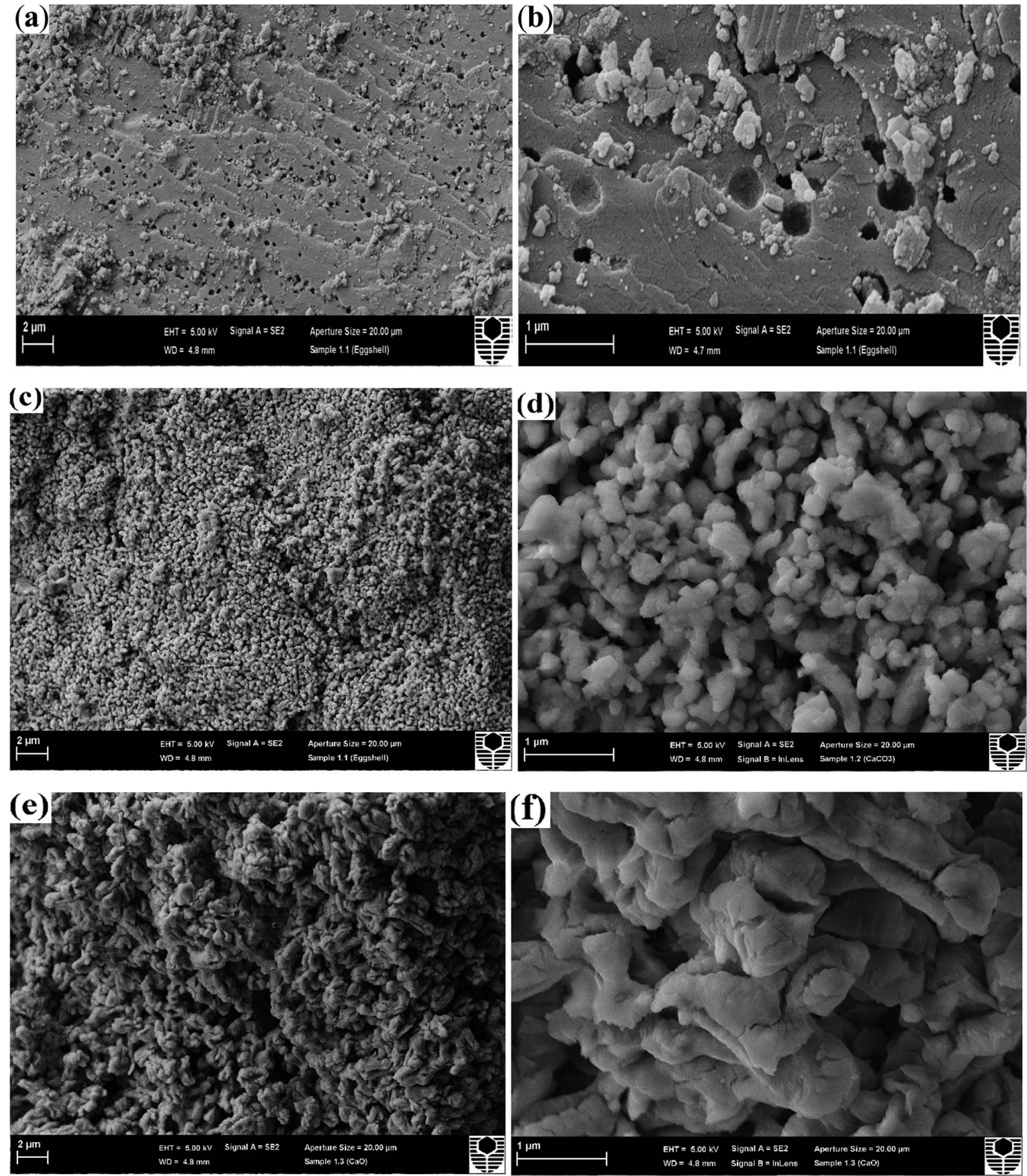

Fig. 3 SEM secondary electron images of the chicken eggshell (a and b) as-crushed and calcined at: (c and d) 600 and (e and f) $900{ }^{\circ} \mathrm{C}$ at low (left) and high (right) magnification views showing the morphological changes occurring with temperature. 
standard pattern for calcite (JCPDS card no. 005-0586). The narrow diffraction lines indicate a regular crystalline structure of the calcite polymorph of $\mathrm{CaCO}_{3}$. Except for the (104) peak (Fig. 1a and b), the intensity of the other diffraction peaks are weak indicating a preferred orientation. For the $900^{\circ} \mathrm{C}$ calcined sample (Fig. 1c), thermal decomposition of calcite resulted in a topotactic reaction forming $\mathrm{CaO}$ (shown in the following eqn (1)). ${ }^{14} \mathrm{CaO}$ was stored in a desiccator to avoid from moisture and ambient atmosphere.

$$
\mathrm{CaCO}_{3}(\mathrm{~s}) \rightarrow \mathrm{CaO}(\mathrm{s})+\mathrm{CO}_{2}(\mathrm{~g})\left(\text { at } 900{ }^{\circ} \mathrm{C}\right)
$$

The diffraction pattern (Fig. 1c) agreed well with the reference pattern for $\mathrm{CaO}$ (JCPDS card no. 037-1497) confirming the formation of $\mathrm{CaO}$ crystalline product resulted from a decomposition of calcite in air. The results are similar to those reported for this material in the literature. ${ }^{14,15}$ To get more insights into the temperature at which this decomposition initiates, XRD patterns were obtained during in situ heating of the biowaste eggshell from room temperature to $900{ }^{\circ} \mathrm{C}$ (Fig. 2). Up to $750{ }^{\circ} \mathrm{C}$, there were only minor shifts in reflection at $21^{\circ} \mathrm{C}$ due to thermal expansion-induced lattice parameter changes, indicating that no phase changes took place. However, above $800{ }^{\circ} \mathrm{C}$, the patterns changed significantly with the evolution of new peaks indicating decomposition of calcite into $\mathrm{CaO}$. An increase in the peak intensities for $\mathrm{CaO}$ was found to occur on increasing the temperature to $900{ }^{\circ} \mathrm{C}$. This confirmed the results of the ex situ XRD on as-crushed and calcined eggshell, concluding the crushed eggshell material is $\mathrm{CaCO}_{3}{ }^{13}$ and a calcined product is $\mathrm{CaO}^{14}$ at a lowest possible temperature of $900{ }^{\circ} \mathrm{C}$. The thermogravimetric analysis (TGA) of the precursor eggshell powder is shown in Fig. S1. $\dagger$ Eggshell has an activation energy of $47.83 \mathrm{kcal} \mathrm{mol}^{-1}$, energy ${ }^{15}$ required to initiate a thermal decomposition, and then further energy required to changes occur in nucleation of crystallites and structure. A weight loss of $1.5 \%$ up to $220{ }^{\circ} \mathrm{C}$ was due to the evaporation of some surface moisture and structural water in the material. From $220^{\circ} \mathrm{C}$ to $500{ }^{\circ} \mathrm{C}$, weight loss was further increased by $2 \%$ which is the result of decomposition/oxidation of the organic material. Overall, a weight loss of only $7 \%$ was seen up to $720^{\circ} \mathrm{C}$, showing considerable structural stability of the $\mathrm{CaCO}_{3}$ material. The thermal decomposition (calcination) of $\mathrm{CaCO}_{3}$ initiates from $720{ }^{\circ} \mathrm{C}$ forming a product of $\mathrm{CaO}$ at around $850{ }^{\circ} \mathrm{C}$ (agreeing well with the in situ XRD) reflecting a significant
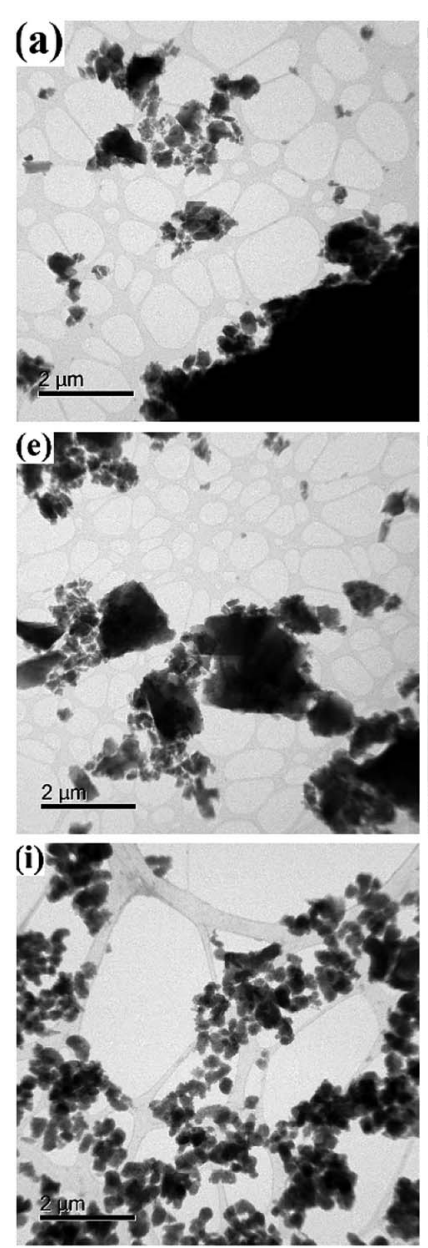

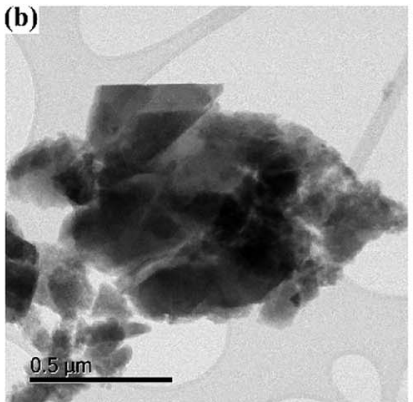

(f)
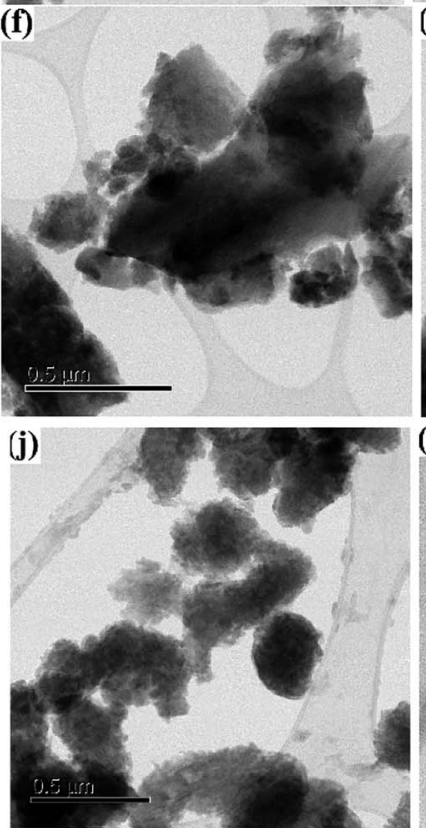
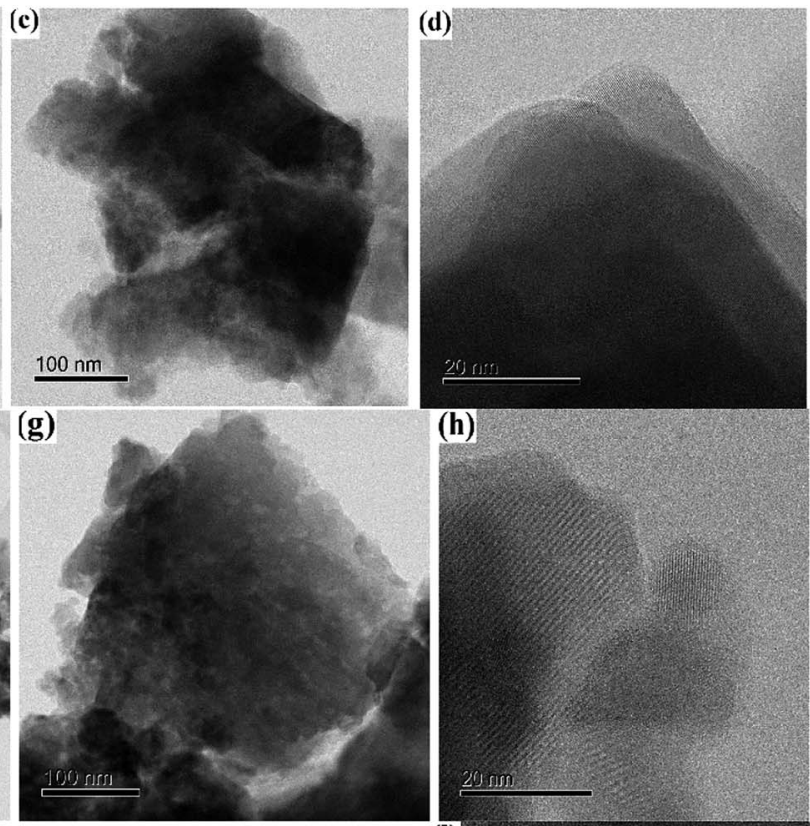

(h)
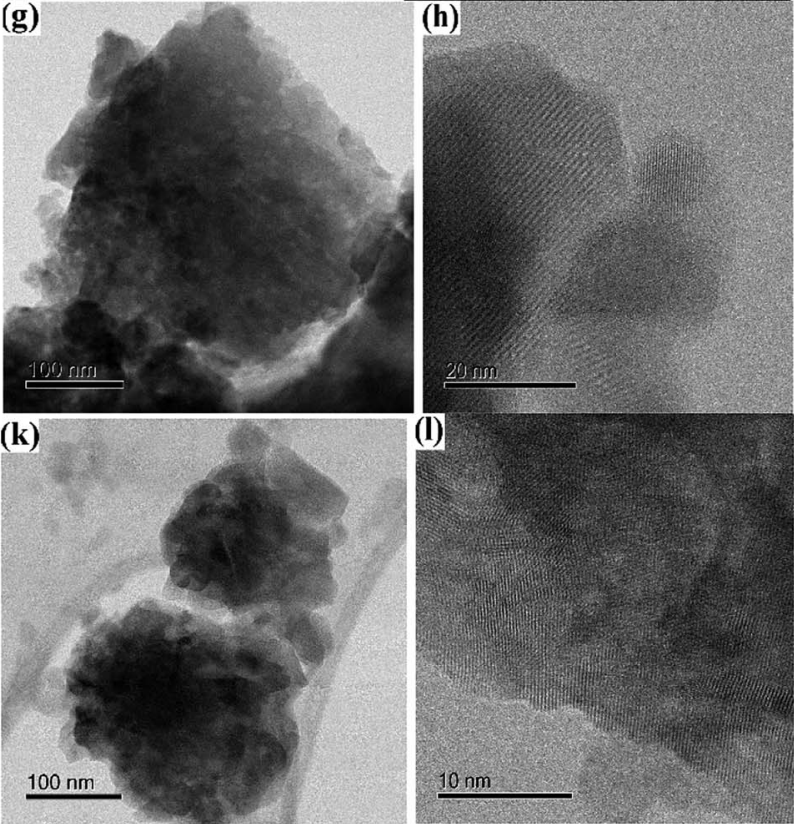

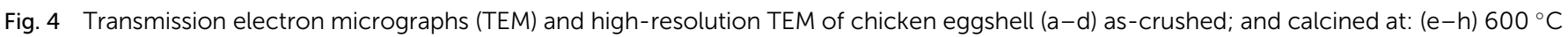
and $(\mathrm{i}-\mathrm{l}) 900^{\circ} \mathrm{C}$. 
weight loss of overall $54 \%$. The theoretical mass compositional loss 55.95\% calculated based on molecular weight for the reactant and products shown in eqn (1) is in good agreement with the actual compositional mass loss observed through TGA analysis.

\section{Textural evolution: FESEM and TEM observations}

Changes in the morphology of the eggshell samples with the influence of calcining temperature was investigated using field emission scanning electron microscopy (FESEM) images are shown in Fig. 3. The crystallites of the as-crushed eggshell (Fig. 3a and b) have an irregular surface structure with pores of around $200 \mathrm{~nm}$. These images are similar to those reported for the eggshell and also pure calcite crystals. ${ }^{16}$ As the temperature is increased $\left(600{ }^{\circ} \mathrm{C}\right)$, a granular surface structure developed with a particulate size of few hundred nm (Fig. $3 \mathrm{c}$ and d). The surface was highly porous. After calcination at $900{ }^{\circ} \mathrm{C}$, Fig. 3e and $\mathrm{f}$, reveals a random assembly of individual micron-sized grains aggregated to form a densely packed structure. The phase evolution observed in the XRD patterns and the SEM images suggests that the $\mathrm{CaCO}_{3} / \mathrm{CaO}$ transformation involves a change in crystallography and this is consistent with the literature. ${ }^{\mathbf{1 4}}$ The corresponding elemental dispersive analysis (EDS) analysis (in Fig. S2 $\dagger$ ) of these samples showed invariably a representative peaks for $\mathrm{Ca}$ and $\mathrm{O}$ for all the samples. Minor peaks from $\mathrm{Mg}$ and $\mathrm{C}$ were also detected in the as-crushed eggshells, which is as expected.

Transmission electron microscopy (TEM) was used to determine the characteristics of the various materials. Ascrushed eggshell TEM images (Fig. 4a-d) reveal generally irregular shapes that justify the high surface area of these nanoparticles. Bright field TEM imaging of the eggshell (Fig. 4a and b) showed the calcite crystals to be dense and angular with a range of particle sizes $(30-500 \mathrm{~nm})$. After calcination at $600{ }^{\circ} \mathrm{C}$ (Fig. 4e-h), the particle shapes became more rounded and irregular and porosity (bright regions) was present inside the larger crystallite (Fig. 4g). After calcination at $900{ }^{\circ} \mathrm{C}$ (Fig. 4i-l), the bright field image showed rounded particles of about 100$200 \mathrm{~nm}$. These contained distinct nanocrystals with diameters of up to $50 \mathrm{~nm}$ along with porosity (Fig. 4k). The corresponding high-resolution TEM image (Fig. 4l) shows the porous and nanocrystalline nature. The nucleation and growth of $\mathrm{CaO}$ crystals from the $\mathrm{CaCO}_{3}$ parent resulted in the particles having a roughened surface texture (Fig. $4 \mathrm{j}$ and $\mathrm{k}$ ) compared to those at lower temperature. A very similar feature has been reported by Sirivat et al. ${ }^{17}$ In the intermediate temperature of $600{ }^{\circ} \mathrm{C}$, no prominent changes in surface morphology relative to room temperature occurred (Fig. 4e-h), the morphology being similar
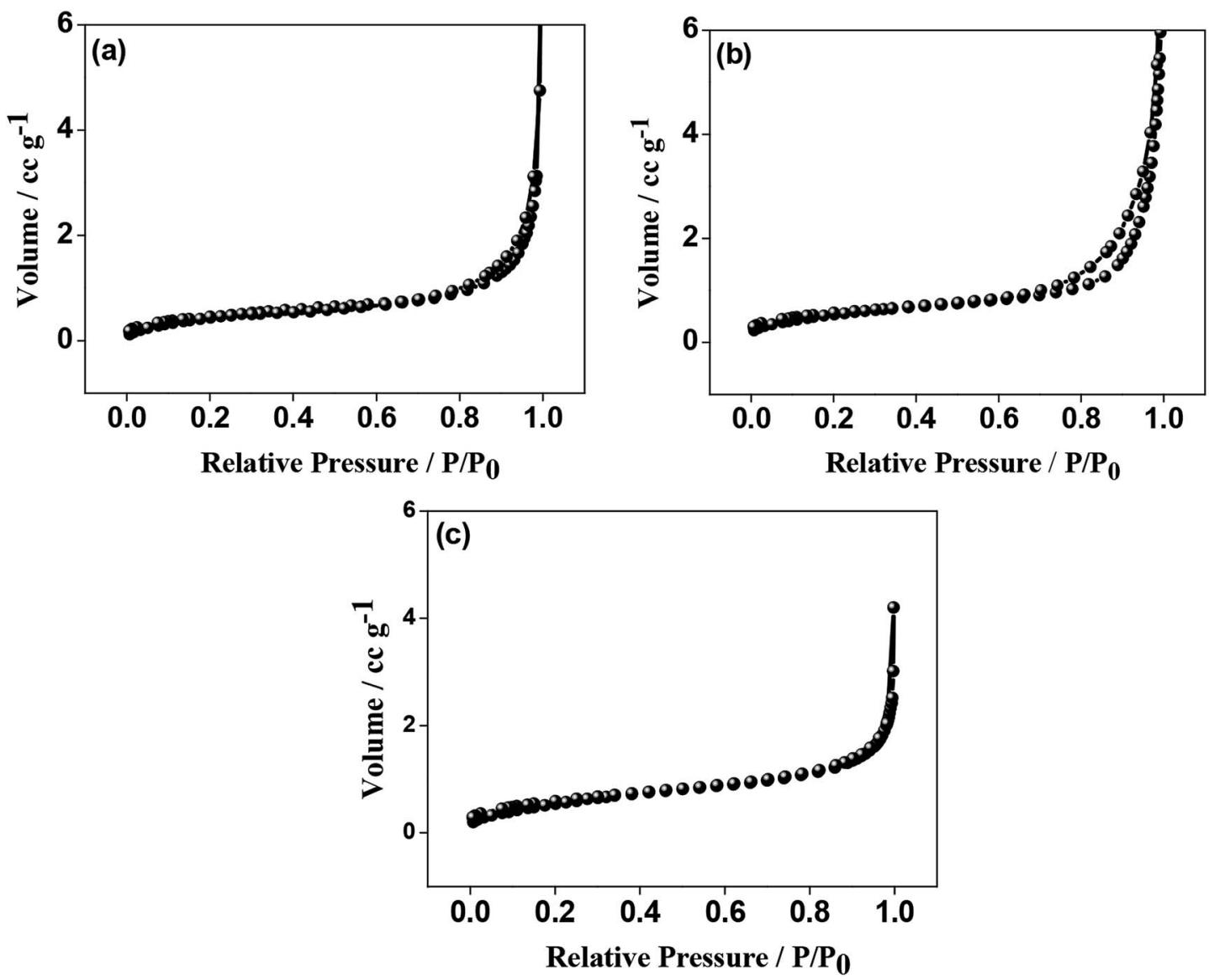

Fig. 5 Nitrogen adsorption and desorption isotherm of chicken eggshell (a) as-crushed; and calcined at: (b) $600^{\circ} \mathrm{C}$ and (c) $900{ }^{\circ} \mathrm{C}$. The isotherm for the three samples are quite similar reflected by the isotherm of type II. 
to that of the crushed calcite. This is in accordance with the results observed from XRD and TGA analyses.

\section{Surface analyses: BET and XPS studies}

The $\mathrm{N}_{2}$ adsorption-desorption isotherms for the as-crushed eggshells, calcined eggshell nanoparticles at different temperatures are shown in Fig. 5. All the samples consisted of a welldeveloped porous adsorbent with a nature of loose aggregates, reflected by the isotherm of type II. ${ }^{\mathbf{1 8}}$ The Brunauer-EmmettTeller (BET) surface area of the as-crushed eggshell was 48.22 $\mathrm{m}^{2} \mathrm{~g}^{-1}$ and the cumulative pore size diameter and volume were $12.75 \mathrm{~m}^{2} \mathrm{~g}^{-1}$ and $0.0067 \mathrm{~cm}^{3} \mathrm{~g}^{-1}$ respectively. In the case of the calcined $600{ }^{\circ} \mathrm{C} / 900{ }^{\circ} \mathrm{C}$ eggshell, the BET surface area was reduced to $21.95 / 10.07 \mathrm{~m}^{2} \mathrm{~g}^{-1}$ and the cumulative pore size diameter and volume were 10.35/8.68 $\mathrm{m}^{2} \mathrm{~g}^{-1}$ and 0.0582/0.0367 $\mathrm{cm}^{3} \mathrm{~g}^{-1}$ respectively. The observed surface area of CaO may not be amenable for surface adsorption/desorption mechanism but the intrinsic nature of $\mathrm{Ca}$ material could support the electrochemical phenomenon. It is also customary to note that the accessible active surface area of having $10.07 \mathrm{~m}^{2} \mathrm{~g}^{-1}$ exposed in electrolyte play an important role in providing higher capacitance but overgrowth of $48.22 \mathrm{~m}^{2} \mathrm{~g}^{-1}$ result in reduced volume thus reducing the capacitance (as discussed in the Electrochemical section).

X-ray photoelectron spectroscopy (XPS) was used to determine the chemical (oxidation) states of the elements present in the eggrshell sample both as-crushed and synthesized at $900{ }^{\circ} \mathrm{C}$.
A typical XPS wide-scan spectrum is shown in Fig. S3.† Ca, C, and $\mathrm{O}$ were observed in both the samples. Nitrogen was also detected in the as-crushed sample, at less than 2 atom\%, and is likely derived from protein in the eggshell membrane. The elemental compositions of the two samples are summarized in Table S1. $\uparrow$ The high-resolution XPS spectra of $\mathrm{Ca} 2 \mathrm{p}, \mathrm{O} 1 \mathrm{~s}$, and $\mathrm{C}$ $1 \mathrm{~s}$ were processed using a Shirley background correction were fitted with Gaussian-Lorentzian line shapes (Fig. 6 and 7). The binding energy value for $\mathrm{Ca}$ is in accordance with the reported values for $\mathrm{CaCO}_{3}$ and $\mathrm{CaO}$ in the literature. The Ca 2p spectrum in Fig. 6a exhibits spin-orbit doublet peaks of $2 \mathrm{p}_{3 / 2}$ and $2 \mathrm{p}_{1 / 2}$ at $346.8 \mathrm{eV}$ and $350.3 \mathrm{eV}$, respectively. The $3.5 \mathrm{eV}$ separation of these peaks is consistent with $\mathrm{Ca}$ in the $2+$ oxidation state. ${ }^{\mathbf{1 9 , 2 0}}$ For the material produced at $900{ }^{\circ} \mathrm{C}$ the peak positions of $\mathrm{Ca} 2 \mathrm{p}$ (Fig. 7a) are unchanged but their intensity is varied to a small extent. Fig. $6 \mathrm{~b}$ and $7 \mathrm{~b}$ shows the deconvoluted $\mathrm{O}$ 1s spectra exhibiting two peaks, the primary peak being around $531 \mathrm{eV}$ is associated with oxygen in the inorganic Ca compounds, while the secondary peak around $532.6 \mathrm{eV}$ is attributed to organic oxygen-containing species. ${ }^{21}$ Fig. $6 \mathrm{c}$ and $7 \mathrm{c}$ shows the $\mathrm{C} 1 \mathrm{~s}$ spectra fitted to four component peaks at around 285, 286, and 288 , and $289 \mathrm{eV}$. The first three are assigned to $\mathrm{C}-\mathrm{C}, \mathrm{C}-\mathrm{O}$, and $\mathrm{C}=\mathrm{O}$, respectively, and are likely due to adventitious carbon contamination. The fourth is attributable to carbonate. The $\mathrm{Ca} /$ $\mathrm{CO}_{3}$ ratio is $0.8,0.9$, and 1.2 for the as-crushed, $600{ }^{\circ} \mathrm{C}$, and $900^{\circ} \mathrm{C}$ samples, respectively, so all are at around $1: 1$. The effect of temperature on crystallinity and particle size may have no
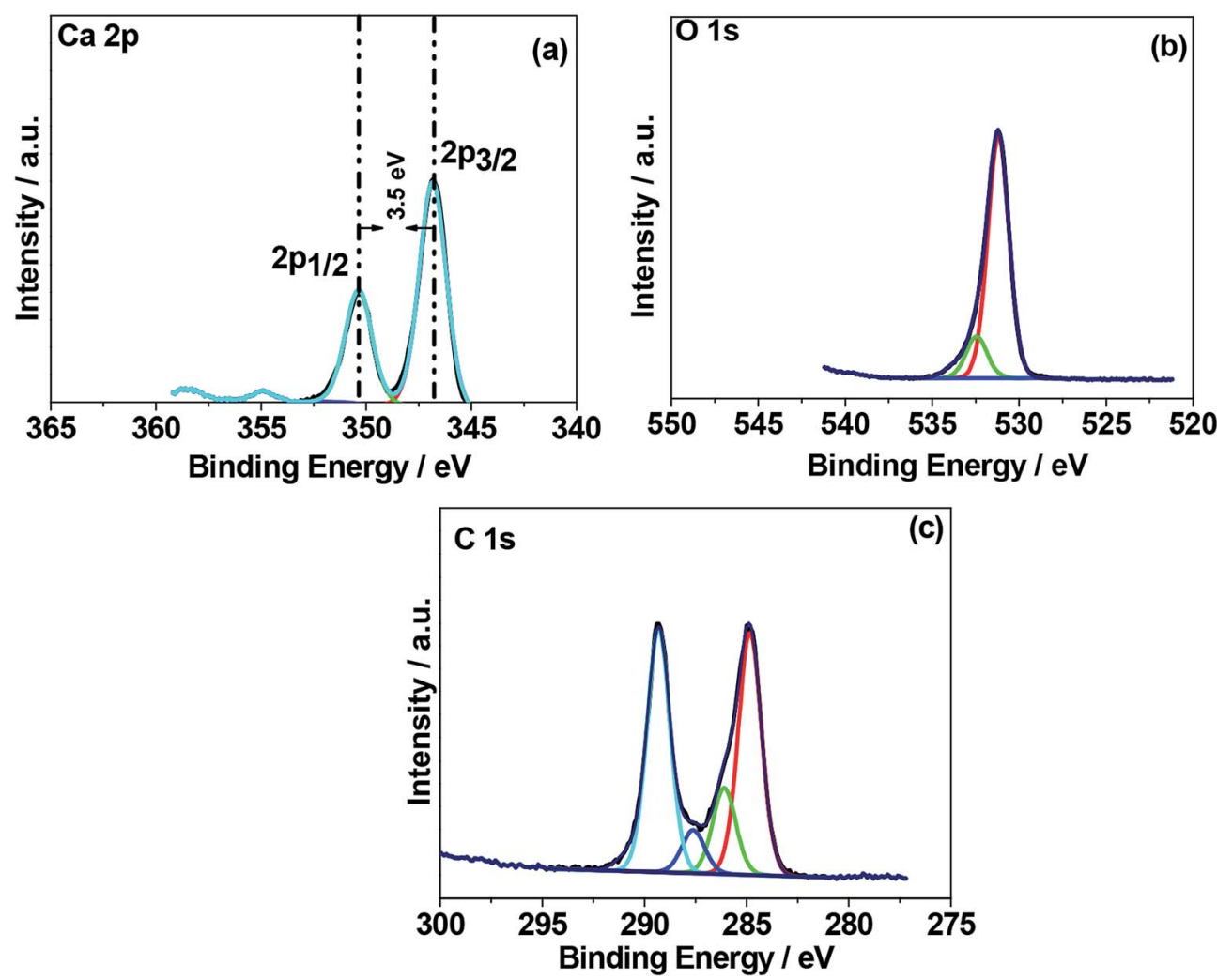

Fig. 6 X-ray photoelectron spectroscopy (XPS) spectra of chicken eggshell as-crushed. High resolution spectra for regions (a) Ca 1s, (b) C 1s, and (c) $\mathrm{O} 1 \mathrm{~s}$. 
effect on the Ca oxidation state and therefore no changes are observed in the binding energies of the elements in both the obtained products such as $\mathrm{CaCO}_{3}$ and $\mathrm{CaO}$. As stated earlier, microscopy results have not definite results in discriminating between $\mathrm{CaCO}_{3}$ and $\mathrm{CaO}$ products. The XPS data for the three samples shows little chemical difference between them.

\section{Electrochemical characterization}

To verify the electrochemical performance of as-crushed eggshells and compare the mechanism involved with calcined eggshell nanoparticles synthesized at different temperatures $600{ }^{\circ} \mathrm{C}$ and $900{ }^{\circ} \mathrm{C}$, cyclic voltammetric and galvanostatic measurements were carried out and the results are shown in Fig. 8-10. When $\mathrm{CaO}$ is exposed to aqueous based electrolyte, it may form slaked lime $\mathrm{Ca}(\mathrm{OH})_{2}$ before initiating any electrochemical reactions.

Initially, we tried to examine the as-crushed eggshell as a working electrode in the individual potential regions (positive and negative) to test the potential to store energy by using a reference $\mathrm{Hg} / \mathrm{HgO}$ electrode and the Pt wire as a counter electrode. The cyclic voltammetric curves plotted against potential are shown in Fig. 8a. The sweep was started in the forward (oxidation) direction and then reversed (reduction) back to the initial potential at a sweep rate of $2 \mathrm{mV} \mathrm{s}^{-1}$. For positive regions, the electrochemical window between 0 and $0.5 \mathrm{~V}$ was used and for negative regions a window between 0 and $-1.0 \mathrm{~V}$ was chosen. It can be seen in the Fig. $8 \mathrm{a}$ that the plots in the respective regions are quite different. In the negative region, a large voltammogram resulted compared with the positive region, implying more charge can be stored at negative potentials. ${ }^{22}$ The curve in the negative region is typical of capacitive behaviour exhibiting quasi-box/rectangular like curve $^{23,24}$ while the curve in the positive region in Fig. 8a indicates it is less electrochemically active but still possesses a well-defined curve albeit over a small current range. In both the regions, the electrochemical reactions do not involve any electron transfer process in the eggshell, as there is no evidence of redox peaks in Fig. 8a. Instead, $\mathrm{OH}^{-}$ions from the $\mathrm{NaOH}$ electrolyte adsorb/ desorb during the oxidation and reduction processes, ${ }^{24}$ not limited by ion diffusion. Fig. 8b-d compares the CV curves in various potential regions at various sweep rates $\left(2 \mathrm{mV} \mathrm{s}^{-1}\right.$ to $20 \mathrm{mV}$ $\left.\mathrm{s}^{-1}\right)$. Faster scan rates $\left(\geq 5 \mathrm{mV} \mathrm{s}^{-1}\right)$ lead to a decrease in the size of a diffusion layer and hence a larger area CV curve with higher currents results. As the current increases linearly with the square root of the applied sweep rate, the electrochemical process is reversible. Interestingly, the plots in the negative region (Fig. 8c) span a much larger current range than the positive plots while retaining the same general shape as the positive region (Fig. 8b). This shows that even though the as-crushed eggshell has a wide voltage window it is more suitable as an anode. Fig. 8d shows the plots for the full electrochemical window, comprising positive and negative regions. These show that the eggshell exhibits electrochemically reversible behaviour. The cell voltage is the absolute value of the potential window studied (from $-1.0 \mathrm{~V}$ to $+0.5 \mathrm{~V}$ ) which is of $1.5 \mathrm{~V}$. Fig. 8e shows the galvanostatic charge-discharge
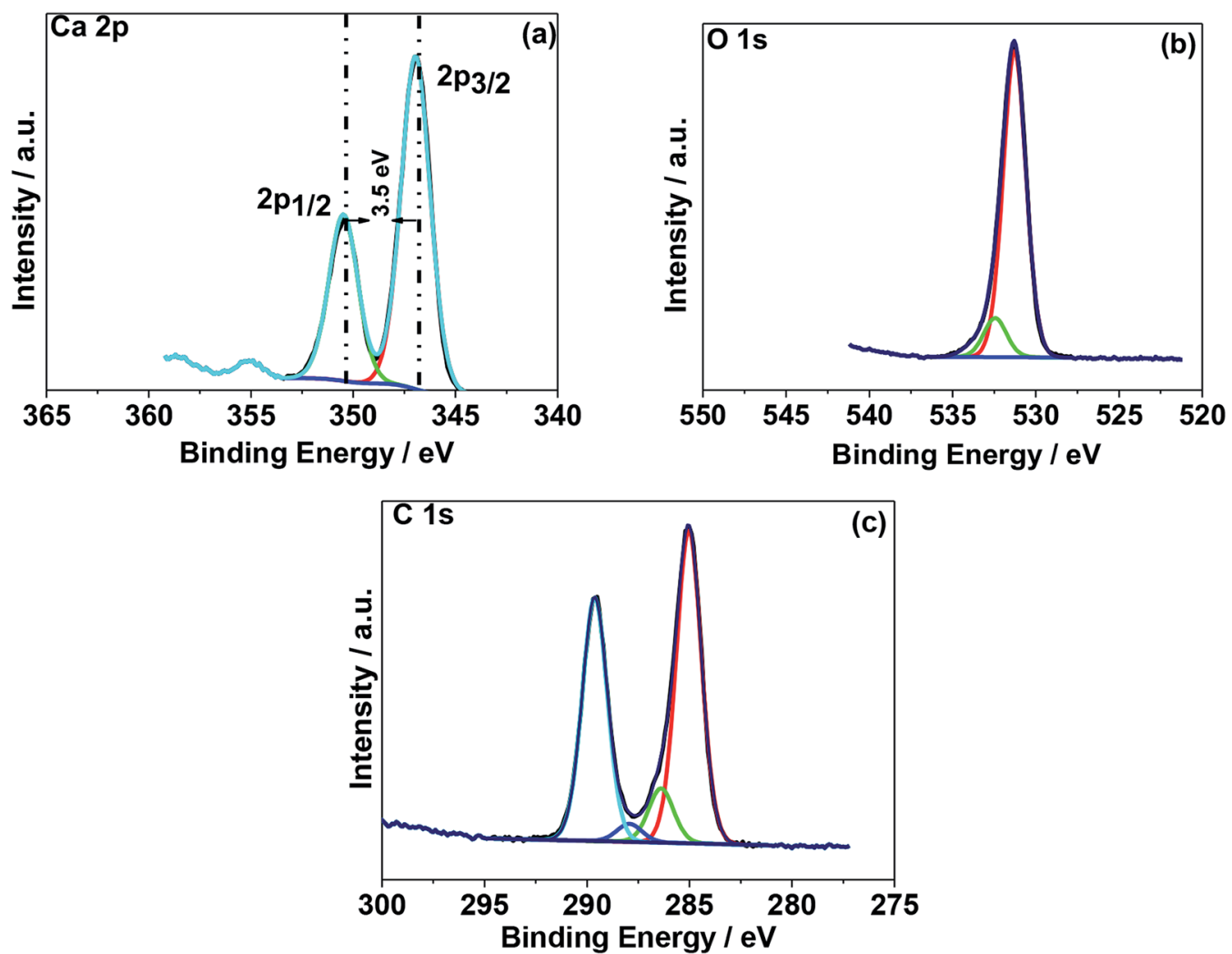

Fig. 7 X-ray photoelectron spectroscopy (XPS) spectra of chicken eggshell calcined at $900^{\circ} \mathrm{C}$. High resolution spectra for regions (a) Ca $1 \mathrm{~s}$, (b) C $1 \mathrm{~s}$, and (c) $01 \mathrm{~s}$. 
of the single electrode (eggshell) in $\mathrm{NaOH}$ electrolyte. The chargedischarge curves are nearly symmetrical for both the positive and negative regions. This is consistent with the CV curves shown earlier (Fig. 8a and b) corresponding to the discharge capacitance of $10 \mathrm{~F} \mathrm{~g}^{-1}$, and $24.5 \mathrm{~F} \mathrm{~g}^{-1}$, respectively. The shape of the chargedischarge curve for the full region is not perfectly symmetric, indicating a pseudo-capacitive behaviour, ${ }^{24}$ and the discharge capacitance was $37 \mathrm{~F} \mathrm{~g}^{-1}$.

For the calcined eggshell at a $600{ }^{\circ} \mathrm{C}$, the $\mathrm{CV}$ and chargedischarge plots are shown in Fig. 9a-e. The shape of the curves are similar to those of as-crushed (shown in Fig. 8a-e) but the curves in all the regions are more well-defined with a discharge capacitances of $15 \mathrm{~F} \mathrm{~g}^{-1}, 30 \mathrm{~F} \mathrm{~g}^{-1}$, and $48 \mathrm{~F} \mathrm{~g}^{-1}$ for positive, negative and full region, respectively. This compares with 10 , 24.5 and $37 \mathrm{~F} \mathrm{~g}^{-1}$ respectively for the corresponding crushed eggshell results. The observed improvement in the performance at a higher temperature may be due to activation of the eggshell sites that enhances the mobility of the $\mathrm{OH}^{-}$ions in the electrode.
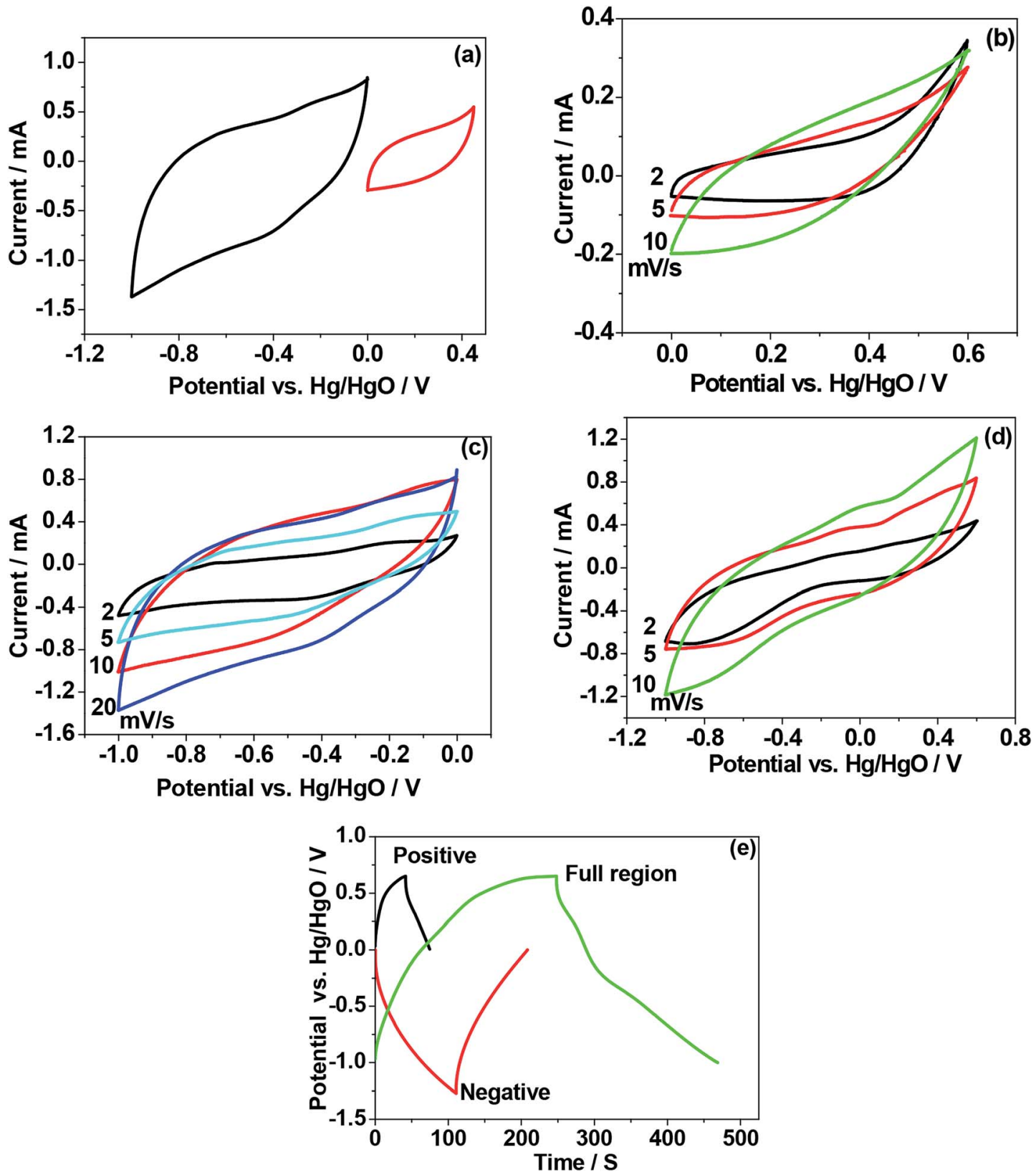

Fig. 8 (a-d) First cyclic voltammetric (CV) curves, and (e) charge-discharge behaviour (three-electrode configuration) of as-crushed eggshell electrode. (a) CV curves of as-crushed eggshell as positive compared with negative region. As-crushed electrode in (b) positive potential window; (c) negative potential window; and (d) full region comprising both positive and negative. (e) Charge -discharge curves of eggshell as a supercapacitor electrode tested in $2 \mathrm{M} \mathrm{NaOH}$ aqueous electrolyte. Both $\mathrm{CV}$ and charge-discharge curves show pseudocapacitive behaviour in the full region. 
Fig. 10 shows the result for the eggshell calcined at a $900{ }^{\circ} \mathrm{C}$. Fig. 10a compares the calcined eggshell in two different potential regions. The $\mathrm{CaO}$ (perhaps $\mathrm{Ca}(\mathrm{OH})_{2}$ ) showed a pseudocapacitive behaviour with a peak $\mathrm{C} 1$ in the negative region while the curve in the positive region appears to be ill-defined with a low current response. Fig. 10b-d compares the CV curves in various potential regions at various scan rates. Obviously, in the positive region, $\mathrm{CaO}$ is not electrochemically active. However, in the negative region (Fig. 10c), the shape and symmetry of the CV curves is retained even at higher sweep rates indicating a high charge transfer stability of the material. This is a pre-requisite for reversible reactions to occur during recharging for any practical applications. In the full potential region (Fig. 10d) that the curves are no longer symmetrical, a reduction (C1) and a corresponding oxidation (A1) peak is observed for this material, resulting in a larger storage capacity. This suggests a charge transfer reaction at the electrode/electrolyte interface, which is typical of pseudo-capacitance behaviour. ${ }^{25}$ The corresponding
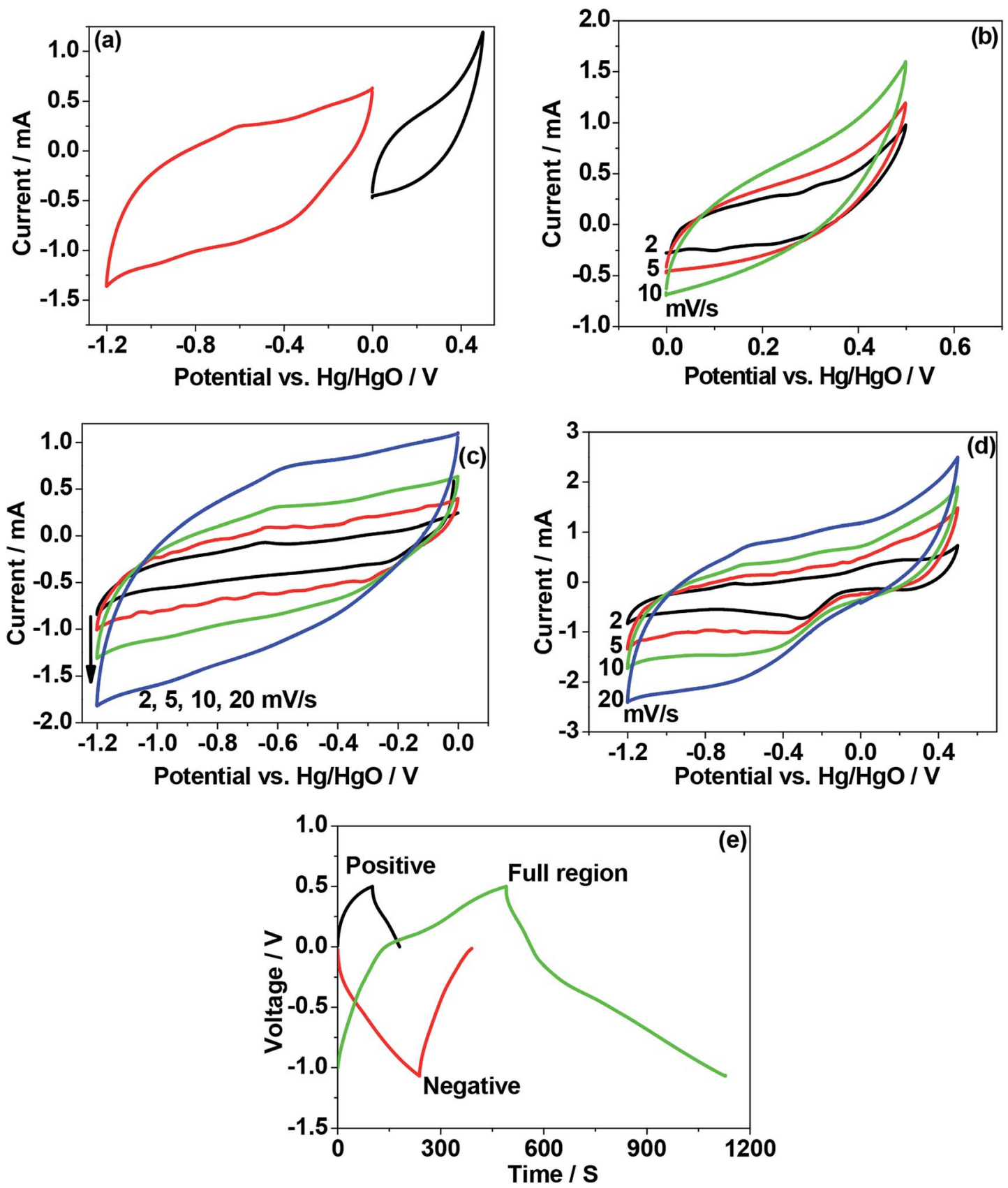

Fig. 9 (a-d) First cyclic voltammetric (CV) curves, and (e) charge-discharge behaviour (three-electrode configuration) of calcined eggshell electrode at a $600^{\circ} \mathrm{C}$. (a) CV curves of calcined eggshell as positive compared with negative region. Calcined electrode in (b) positive potential window; (c) negative potential window; and (d) full region comprising both positive and negative. (e) Charge-discharge curves of calcined eggshell as a supercapacitor electrode tested in $2 \mathrm{M} \mathrm{NaOH}$ aqueous electrolyte. Both $\mathrm{CV}$ and charge-discharge curves show enhanced pseudocapacitive behaviour in the full region with no symmetry curves. 
charge-discharge curve (in Fig. 10e) also confirms that the discharge curves are different in shape from those of usual capacitors, having a plateau-like curve, being larger in the discharge time, implying battery-like behaviour of the electrode. The discharge capacitances are $8 \mathrm{~F} \mathrm{~g}^{-1}, 47.5 \mathrm{~F} \mathrm{~g}^{-1}$, and $65 \mathrm{~F} \mathrm{~g}^{-1}$ for positive, negative and full region, respectively. This compares with $10,24.5$ and $37 \mathrm{~F} \mathrm{~g}^{-1}$ respectively for the corresponding crushed eggshell results. This is a clear indication that the $\mathrm{CaO}$ material can act as an electrode for both battery and supercapacitor applications. The observed electrochemical differences also depends on its impedance characteristics. The electrochemical impedance spectroscopy (EIS) analysis by Nyquist plots, for the three electrodes is compared in Fig. 11. The impedance is sensitive to the synthesis
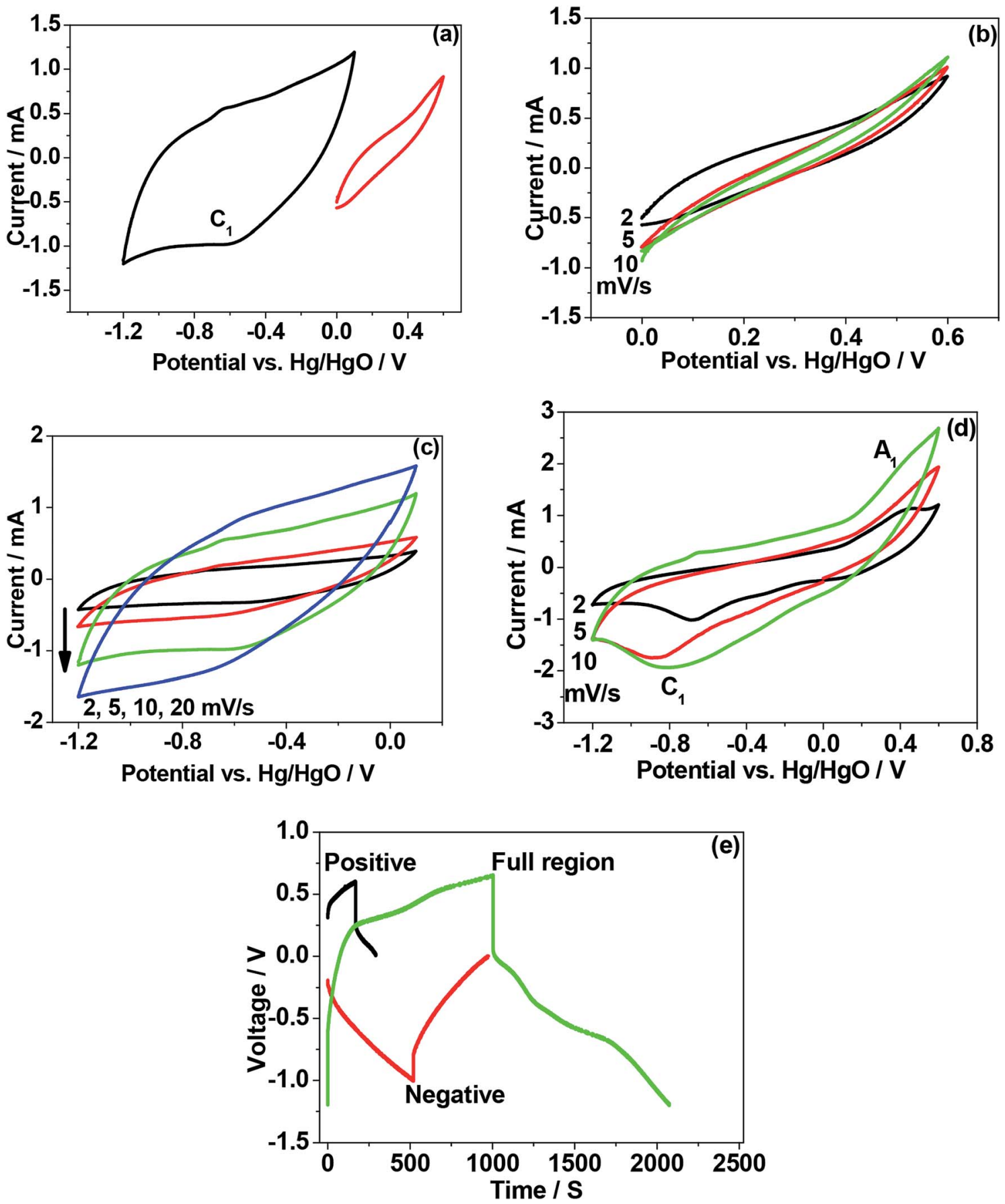

Fig. 10 (a-d) First cyclic voltammetric (CV) curves, and (e) charge-discharge behaviour (three-electrode configuration) of calcined eggshell electrode at a $900^{\circ} \mathrm{C}$. (a) CV curves of calcined eggshell as positive compared with negative region. Calcined electrode in (b) positive potential window; (c) negative potential window; and (d) full region comprising both positive and negative. (e) Charge-discharge curves of calcined eggshell as a supercapacitor electrode tested in $2 \mathrm{M} \mathrm{NaOH}$ aqueous electrolyte. Both $\mathrm{CV}$ and charge-discharge curves show rechargeable battery type behaviour in the full region with asymmetric curves. 
temperature, impedance increases (radius of curvature of arc) with increasing temperature at which the electrode material was formed. The arcs are related to the interfacial charge transfer resistance and double-layer capacitance of the electrode, as reported in the literature. ${ }^{\mathbf{2 6 - 2 9}}$ The proposed six-component equivalent circuit used for the analysis of the EIS spectra has been shown in the Fig. 11. As-crushed eggshell sample (Fig. 11a) shows an arc only in the high frequency region and a sloping trend appeared at high frequency region. The intercept of the Nyquist curve on the real axis exhibits a solution ohmic resistance $\left(R_{\mathrm{S}}\right)$ about $5.2 \Omega$ with a small diameter of the semicircle (charge transfer resistance; $R_{\text {ct }}$ which is of $40 \Omega$ ), while the calcined samples (Fig. 11b and c) both show arcs in both the high and low frequency regions, representing the charge transfer and diffusion process, respectively. ${ }^{30}$ For $900{ }^{\circ} \mathrm{C}$ calcine (Fig. 11c), both the solution ohmic resistance (52 $\Omega$ ) and the charge transfer resistance $(172 \Omega)$ are higher than that of ascrushed eggshell electrode suggesting a pseudocapacitive like material. At low frequencies, ions from the aqueous $\mathrm{NaOH}$ electrolyte diffuse into the eggshell material, representing a battery-like faradaic reactions that results in pseudocapacitance. The slope of the line at the low-frequency region in the Nyquist plot is called the Warburg resistance $\left(W_{\mathrm{o}}\right.$, which is of $1.8 \Omega$ ), deviating from a vertical line, is an indication of high diffusive resistance owing to battery-like behaviour. ${ }^{31}$ The resistance $\left(R_{\mathrm{SEI}}\right.$; which is of $\left.42.3 \Omega\right)$ and capacitance $\left(C_{\mathrm{SEI}}\right.$; which is of $2.33 \mu \mathrm{F}$ ) of the solid electrolyte interphase (SEI) represent the solid electrolyte interface layer ${ }^{32,33}$ on the surface of the eggshell electrodes, while $C_{\mathrm{dl}}{ }^{34}$ is the double layer of charge formed at the interface. This is a typical characteristic nature of the temperature dependence of the eggshell material, contributing from faradaic and non-faradaic behaviour. Overall, the

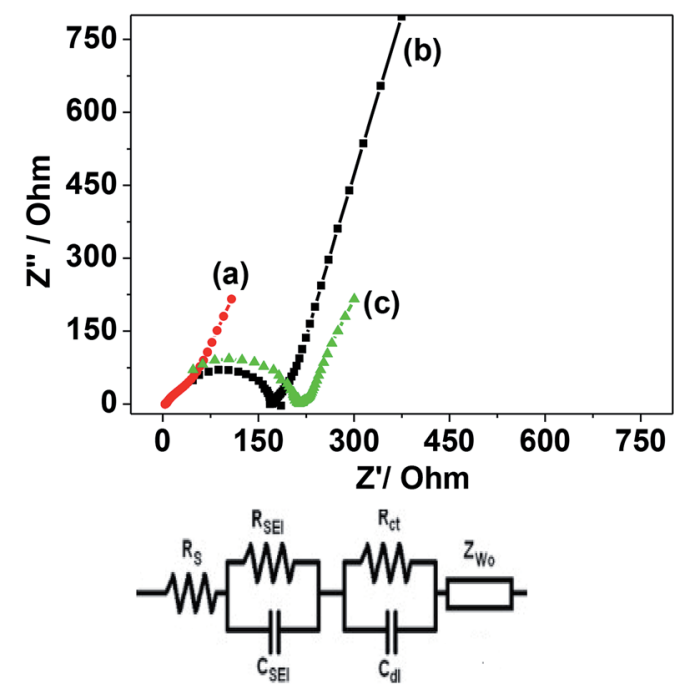

Fig. 11 Nyquist plot comparing the impedance in high frequency region and capacitive/battery behaviour in low frequency region for chicken eggshell (a) as-crushed; and calcined at: (b) $600{ }^{\circ} \mathrm{C}$ and (c) $900{ }^{\circ} \mathrm{C}$. The capacitive and battery type behaviour is seen for $600^{\circ} \mathrm{C}$ and $900{ }^{\circ} \mathrm{C}$, respectively. The corresponding equivalent circuit is shown below the plot. impedance spectra suggests that as-crushed eggshell is capacitive whereas the $900{ }^{\circ} \mathrm{C}$ calcined eggshell is a battery type material. To test the cyclability of the $900{ }^{\circ} \mathrm{C}$ calcine, charge and discharge measurements were repeated for 1000 cycles and the results are shown in Fig. 12. The available discharge capacitance value of $55 \mathrm{~F} \mathrm{~g}^{-1}$ at a current density of $0.15 \mathrm{~A} \mathrm{~g}^{-1}$ is retained after 1000 cycles with a $100 \%$ efficiency. Fig. 13 shows charge-discharge curves at various current rates for the $900{ }^{\circ} \mathrm{C}$ calcined electrode. All the curves are reversible and the material is suitable for high current rate applications.

We have investigated the performance of this system in low power battery applications through applying a very low scan rate. The nature of the $\mathrm{CaO}$ electrode behaved very differently (in Fig. $\mathrm{S} 4 \dagger)$ at a very low sweep rate $\left(0.5 \mathrm{mV} \mathrm{s}^{-1}\right)$ exhibiting pair of reduction peaks (cathodic; $\mathrm{C} 1$ and $\mathrm{C} 2$ ) and oxidation peaks (anodic; A1 and A2) in the negative potential region indicating diffusion-controlled reaction kinetics (as evidently shown in Fig. 11c). Across the entire voltage window, prominent redox peaks are clearly visible, indicating typical rechargeable batteries behaviour in the form of redox peaks. Based on these results, we suggest that the calcined eggshells with a porous architecture are strong anode candidates and the electrochemical performance is comparable to that of values reported in the literature ${ }^{35,36}$ with an equivalent of $\sim 40 \mathrm{~mA} \mathrm{~h} \mathrm{~g}^{-1}$ for calcium-based batteries in aqueous electrolytes. Therefore, eggshells-derived materials have the potential for both batteries and supercapacitor applications similar to that reported in the calcium-ion batteries ${ }^{37}$ and phosphorous incorporated nanoporous carbons pseudocapacitors in organic electrolytes. ${ }^{38}$

To this end, a practical symmetrical supercapacitor has been fabricated, comprising chicken eggshell as-crushed electrode coupled with calcined at $900{ }^{\circ} \mathrm{C}$ electrode and its electrochemical performance is shown in Fig. 14. Both cyclic voltammetric and its corresponding charge-discharge curves implies a quasi-rectangular shape and almost linear charge discharge curves with a discharge capacitance of $53.57 \mathrm{~F} \mathrm{~g}^{-1}$ at an energy density of $14.5 \mathrm{~W} \mathrm{~h} \mathrm{~kg}^{-1}$ providing a high power density of $525 \mathrm{~W} \mathrm{~kg}^{-1}$. This high power density value is suitable for high power applications.

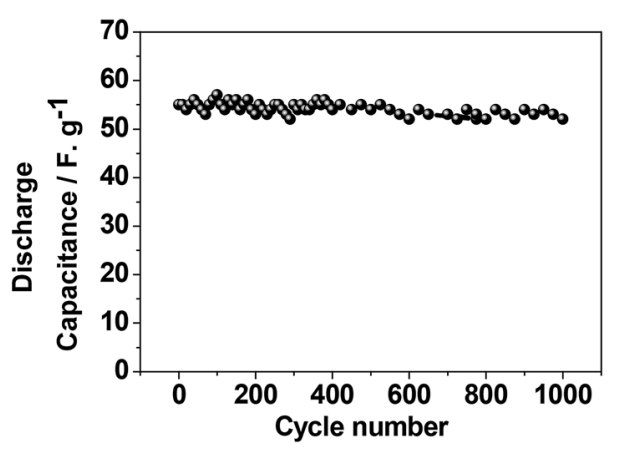

Fig. 12 Cycling stability of the calcined chicken eggshell at $900{ }^{\circ} \mathrm{C}$ exhibiting a discharge capacitance of $55 \mathrm{~F} \mathrm{~g}^{-1}$ having a retention of $100 \%$ after 1000 cycles. 

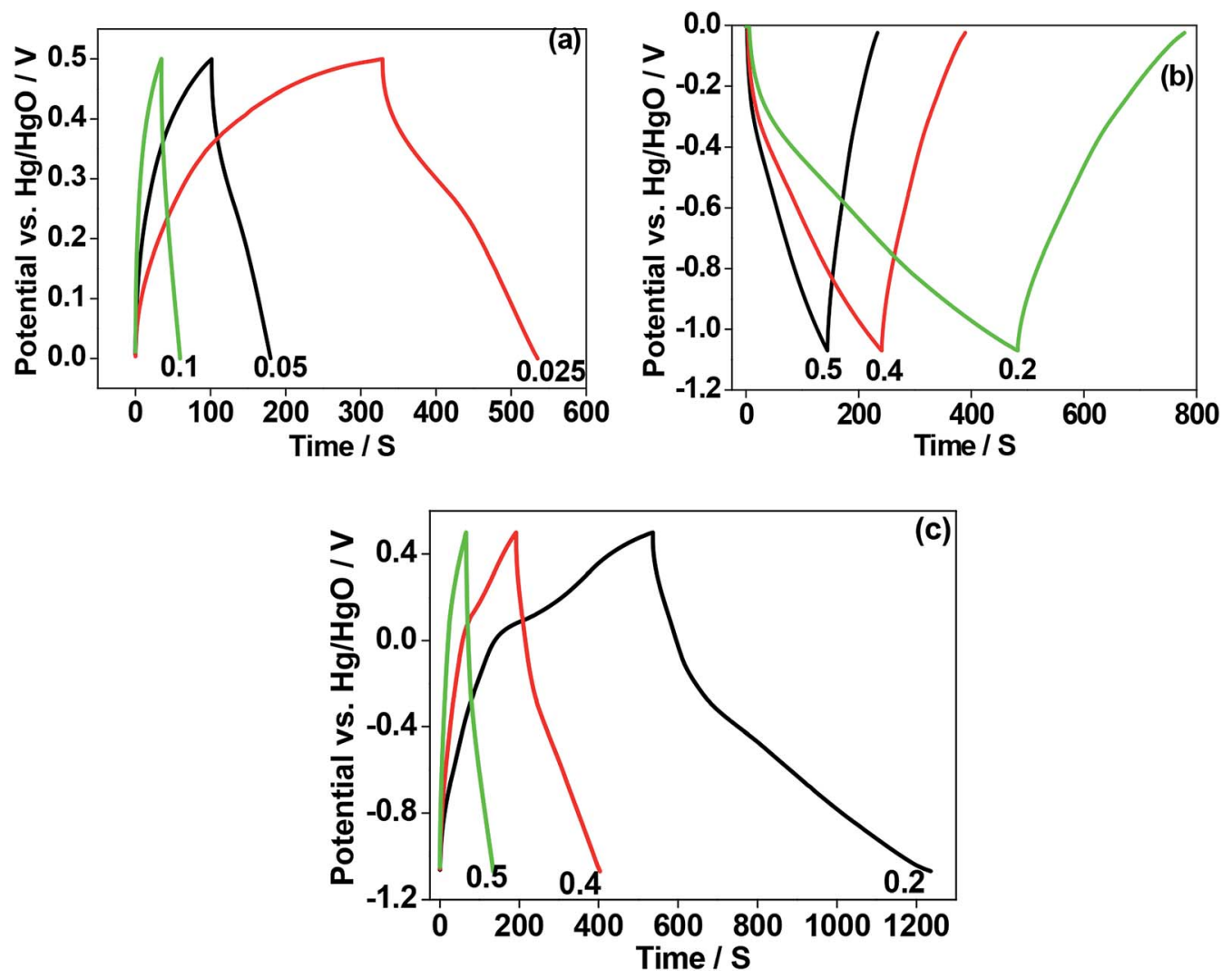

Fig. 13 Charge-discharge curves of chicken eggshell $900^{\circ} \mathrm{C}$ (three-electrode configuration) in (a) positive potential window (0.5 V); (b) negative potential window (-1.0 V); and (c) full region comprising both positive and negative (1.5 V) in $\mathrm{NaOH}$ aqueous electrolyte. The charge-discharge in the full region curves show pseudocapacitive behaviour. Current densities $\left(\mathrm{A} \mathrm{g}^{-1}\right)$ are denoted in the respective figures.
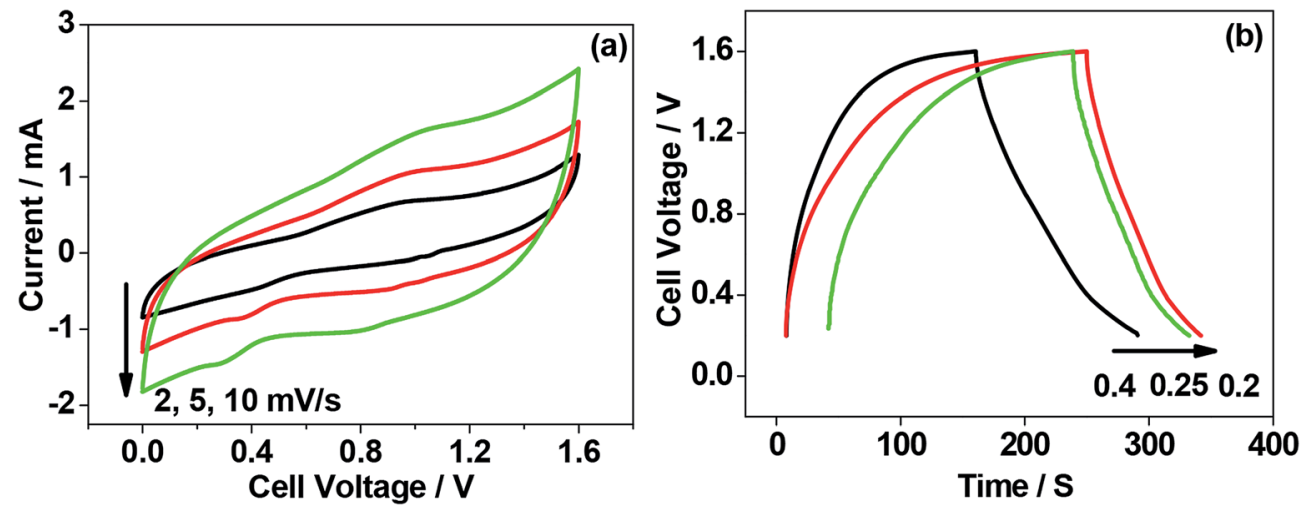

Fig. 14 Symmetrical supercapacitor comprising chicken eggshell as-crushed against calcined at $900{ }^{\circ} \mathrm{C}$. (a) CV curves; and (b) chargedischarge profiles exhibiting a capacitor behaviour. The sweep rates and current density $\left(\mathrm{A} \mathrm{g}^{-1}\right)$ are given in the respective figures.

\section{Conclusions}

We have studied the electrochemical performance of eggshell as a function of calcination temperature and fabricated a symmetrical supercapacitor. The as-crushed eggshell and that calcined at $600{ }^{\circ} \mathrm{C}$ possesses a calcite $\left(\mathrm{CaCO}_{3}\right)$ structure while the material calcined at $900{ }^{\circ} \mathrm{C}$ decomposed into $\mathrm{CaO}$. High temperature XRD and TGA showed that thermal decomposition of calcite initiates at $750{ }^{\circ} \mathrm{C}$. The topotactic $\mathrm{CaCO}_{3} / \mathrm{CaO}$ transformation is associated with a loss of $\mathrm{CO}_{2}$ calcite particles being transformed into agglomerates of much smaller $\mathrm{CaO}$ crystals. The $\mathrm{CaCO}_{3}$ electrode electrochemical properties make it suitable as a cathode while material obtained from eggshell calcined at $900{ }^{\circ} \mathrm{C}$ can be used for an anode. The $\mathrm{CaCO}_{3}$ cathode and the anode $900{ }^{\circ} \mathrm{C}$ exhibited a specific capacitance of 10 and $47 \mathrm{~F} \mathrm{~g}^{-1}$ respectively. Both electrodes showed the ability to perform at positive and negative potentials. However, the $900{ }^{\circ} \mathrm{C}$ calcine outperformed with a capacitance of $55 \mathrm{~F} \mathrm{~g}^{-1}$ (compared 
with $37 \mathrm{~F} \mathrm{~g}^{-1}$ for $\mathrm{CaCO}_{3}$ ) and exhibited a retention of $100 \%$ efficiency after 1000 cycles but still half the value of that of conventionally used activated carbon. The conversion of biowaste destined for landfill (negative value) into a potentially high value energy storage material is an exciting step along the road to sustainable energy development.

\section{Conflicts of interest}

There are no conflicts to declare.

\section{Acknowledgements}

One of the authors (M. M.) acknowledge Murdoch University Vice Chancellor's Small Steps of Innovation Funding in 2018. The TEM work was carried out using a JEOL ARM200F instrument equipment funded by the Australian Research Council (ARC) - Linkage, Infrastructure, Equipment and Facilities (LIEF) grant LE120100104, located at the UOW Electron Microscopy Centre. This work was performed in part at the Australian National Fabrication Facility (ANFF), a company established under the National Collaborative Research Infrastructure Strategy, through the La Trobe University Centre for Materials and Surface Science.

\section{References}

1 A. Evans, V. Stezov and T. J. Evans, Assessment of utility energy storage options for increased renewable energy penetration, Renewable Sustainable Energy Rev., 2012, 16, 414-4147.

2 J. Cho, S. Jeong and Y. Kim, Commercial and research battery technologies for electrical energy storage applications, Prog. Energy Combust. Sci., 2015, 48, 84-101.

3 Z. Wu, L. Li, J.-M. Yan and X.-B. Zhang, Materials design and system construction for conventional and new-concept supercapacitors, Adv. Sci., 2017, 4, 1600382.

4 X. Yu, S. Yun, J. S. Yeon, P. Bhattacharya, L. Wang, S. W. Lee, X. $\mathrm{Hu}$ and H. S. Park, Emergent pseudocapacitance of 2D nanomaterials, Adv. Energy Mater., 2018, 8, 1702930.

5 P. Nakhanivej, X. Yu, S. K. Park, S. Kim, J. Y. Hong, H. J. Kim, W. Lee, J. Y. Hwang, J. E. Yang, C. Wolverton, J. Kong, M. Chhowalla and H. S. Park, Revealing molecular-level surface redox sites of controllably oxidised black phosphorous nanosheets, Nat. Mater., 2019, 18, 156-162.

6 Y. Shi, X. Zhou and G. Yu, Material and structural design of novel binder systems for high-energy, high-power lithiumion batteries, Acc. Chem. Res., 2017, 50, 2642-2652.

7 Y. Fang, J. Zhang, L. Xiao, X. Ai, Y. Cao and H. Yang, Phosphate framework electrode materials for sodium ion batteries, Adv. Sci., 2017, 4, 1600392.

8 C. Liu, Z. G. Neale and G. Cao, Understanding electrochemical potentials of cathode materials in rechargeable batteries, Mater. Today, 2016, 19, 109-123.

9 M. Bobby Kannan and K. Ronan, Conversion of biowastes to biomaterial: An innovative waste management approach, Waste Manag., 2017, 67, 67-72.
10 D. Cree and A. Rutter, Sustainable bio-inspired limestone eggshell powder for potential industrialised applications, ACS Sustainable Chem. Eng., 2015, 3, 941-949.

11 M. Minakshi, H. Visbal, D. R. G. Mitchell and M. Fichtner, Bio-waste chicken eggshells to store energy, Dalton Trans., 2018, 47, 16828-16834.

12 G. A. M. Ali, O. A. Habeeb, H. Algarni and K. F. Chong, CaO impregnated highly porous honeycomb activated carbon from agricultural waste: symmetrical supercapacitor study, J. Mater. Sci., 2019, 54, 683-692.

13 D. Athanasiadou, W. Jiang, D. Goldbaum, A. Saleem, K. Basu, M. C. Pacella, C. F. Bohm, R. C. Chromik, M. T. Hincke, A. B. Rodriquez-Navarro, H. Vali, S. E. Wolf, J. J. Gray, K. H. Bui and M. D. McKee, Nanostructure, ostepontin, and mechanical properties of calcitic avian eggshell, Sci. Adv., 2018, 4, 1-13.

14 C. Rodriguez-Navarro, E. Ruiz-Agudo, A. Luque, A. B. Rodriguez-Navarro and M. O. Huertas, Thermal decomposition of calcite: Mechanisms of formation and textural evolution of $\mathrm{CaO}$ nanocrystals, Am. Mineral., 2009, 94, 578-593.

15 F. S. Murakami, P. O. Rodrigues, C. M. T. de Campos and M. A. S. Silva, Physicochemical study of $\mathrm{CaCO}_{3}$ from egg shells, Food Sci. Technol., 2007, 27, 658-682.

16 M. S. Tizo, L. A. V. Blanco, A. C. Q. Cagas, B. R. B. Dela Cruz, J. C. Encoy, J. V. Gunting, R. O. Arazo and V. I. F. Mabayo, Efficiency of calcium carbonate from eggshells as an adsorbent for cadmium removal in aqueous solution, Sustainable Environ. Res., 2018, 28, 326-332.

17 N. Tangboriboon, R. Kunanuruksapong and A. Sirivat, Preparation and properties of calcium oxide from eggshells via calcination, Mater. Sci.-Pol., 2012, 30, 313-322.

18 G. Aranovich and M. Donohue, Analysis of Adsorption Isotherms: Lattice theory predictions, classifications of isotherms for gas-solid equilibria, and similarities in gas and liquid adsorption behaviour, J. Colloid Interface Sci., 1998, 200, 273-290.

19 C. S. Gopinath, S. G. Hegde, A. V. Ramaswamy and S. Mahapatra, Photoemission studies of polymorphic $\mathrm{CaCO}_{3}$ materials, Mater. Res. Bull., 2002, 37, 1323-1332.

20 M. Ni and B. D. Ratner, Differentiating calcium carbonate polymorphs by surface analysis techniques-an XPS and TOF-SIMS study, Surf. Interface Anal., 2008, 40, 1356-1361.

21 D. R. Baer, D. L. Blanchard, M. E. Engelhard and J. M. Zachara, The interaction of water and $\mathrm{Mn}$ with surfaces of $\mathrm{CaCO}_{3}$ : An XPS study, Surf. Interface Anal., 1991, 17, 25-30.

22 N. Elgrishi, K. J. Rountree, B. D. McCarthy, E. S. Rountree, T. T. Eisenhart and J. L. Dempsey, A Practical Beginner's Guide to Cyclic Voltammetry, J. Chem. Educ., 2018, 95, 197206.

23 B. E. Conway, Transition from supercapacitor to battery behaviour in electrochemical energy storage, J. Electrochem. Soc., 1991, 138, 1539-1548.

24 Y. Wang, Y. Song and Y. Xia, Electrochemical capacitors: mechanism, materials, systems, characterization and applications, Chem. Soc. Rev., 2016, 45, 5925-5950. 
25 P. Simon and Y. Gogotsi, Materials for electrochemical capacitors, Nat. Mater., 2008, 7, 845-854.

26 G. A. M. Ali, E. Megiel, J. Romanski, H. Algarni and K. F. Chong, A wide potential window symmetric supercapacitor by TEMP functionalised MWCNTs, J. Mol. Liq., 2018, 271, 31-39.

27 Y. Gong, D. Li, Q. Fu and C. Pan, Influence of graphene microstructures on electrochemical performance for supercapacitors, Prog. Nat. Sci.: Mater. Int., 2015, 25, 379385.

28 G. A. M. Ali, O. A. G. Wahba, A. M. Hassan, O. A. Fouad and K. F. Chong, Calcium-based nanosized mixed metal oxides for supercapacitor application, Ceram. Int., 2015, 41, 82308234.

29 G. A. M. Ali, M. M. Yusoff, E. R. Shaaban and K. F. Chong, High performance $\mathrm{MnO}_{2}$ nanoflower supercapacitor electrode by electrochemical recycling of spent batteries, Ceram. Int., 2017, 43, 8440-8448.

30 I. Yang, S.-G. Kim, S. H. Kwon, M.-S. Kim and J. C. Jung, Relationships between pore size and charge transfer resistance of carbon aerogels for organic electric doublelayer capacitor electrodes, Electrochim. Acta, 2017, 223, 2130.

31 B.-A. Mei, O. Munteshari, J. Lau, B. Dunn and L. Pilon, Physical interpretations of Nyquist plots for EDLC electrodes and devices, J. Phys. Chem. C, 2018, 122, 194-206.

32 J. Kang, J. Wen, S. H. Jayaram, A. Yu and X. Wang, Development of an equivalent circuit model for electrochemical double layer capacitors (EDLCs) with distinct electrolytes, Electrochim. Acta, 2014, 115, 587-598.

33 Y. Zhang, C. Yuan, K. Ye, X. Jiang, J. Yin, G. Wang and D. Cao, An aqueous capacitor battery hybrid device based on Na-ion insertion-de insertion in $\lambda$ - $\mathrm{MnO}_{2}$ positive electrode, Electrochim. Acta, 2014, 148, 237-243.

34 H.-K. Song, Y.-H. Jung, K.-H. Lee and L. H. Dao, Electrochemical impedance spectroscopy of porous electrodes: the effect of pore size distribution, Electrochim. Acta, 1999, 44, 3513-3519.

35 R. Y. Wang, C. D. Wessells, R. A. Huggins and Y. Cui, Highly reversible open framework nanoscale electrodes for divalent ion batteries, Nano Lett., 2013, 13, 5749-5752.

36 C. H. Lee and S.-K. Jeong, A novel superconcentrated aqueous electrolyte to improve the electrochemical performance of calcium-ion batteries, Chem. Lett., 2016, 45, 1447-1449.

37 R. Gummow, G. Vamvounis, M. Bobby Kannan and Y. He, Calcium-ion batteries: current state-of-the-art and future perspectives, Adv. Mater., 2018, 30, 1801702.

38 S. K. Park, S. H. Kwon, S. G. Lee, M. S. Choi, D. H. Suh, P. Nakhanivej, H. Lee and H. S. Park, $10^{5}$ Cyclable pseudocapacitive Na-ion storage of hierarchically structured phosphorous-incorporating nanoporous carbons in organic electrolytes, ACS Energy Lett., 2018, 3, 724-732. 